\title{
PS Y CHE.
}

\section{THE TROPHI AND THEIR CHITINOUS SUPPOR'TS IN GRACILARIA.}

\author{
BY GEORGE DIMMOCK, CAMBRIDGE, MASS.
}

The papers upon Lithocolletis by Mr. V. T. Chambers, which have appeared from time to time in Psrche, ${ }^{1}$ supplemented by the notes and figures on the same subject contained in his address as retiring president of the Cincinnati Society of Natural History, ${ }^{2}$ inspired me with the desire to study further the mouth-parts of the larvae of Tineina, especially in their earlier stages. The abundance of Gracilaria syringella in the leaves of the lilac ( $S y$ ringa vulgaris), about Leipzig this summer, gave me plenty of material, and the opportunity of studying the larvae under the direction of Professor Leuckart was not lost.

Altho the larvae were so numerous in some of the gardens about Leipzig that scarcely a leaf of the lilac escaped their depredations, I attempted to learn but little of their mode of life. During their early stages, when they have the flattened larval form, they mine in the upper side of the leaf. They then have the form of head and mouth-parts represented in fig. 2, and their legs are mere rudiments. A little

1 Psyche, Nov.-Dec. 1877 [April 1878], v. 2, p. 81-87; May-Aug. [Nov.] 1878, v. 2, p. 137-153; April 1879 , v. 2, p. 227. later they assume the form of head and mouth-parts shown in fig. 3, and begin to eat away all the parenchyma of the leaf, leaving only the upper and lower epidermis; still later they leave the mines and roll the ends of the leaves, feeding within the rolls. Upon changing the form of mouth-parts from that represented in figure 2 to that represented in fig. 4 , true legs are developed, the secretion of silk is begun, and the larvae become more cylindrical. A striking resemblance to the changes which Mr. Chambers has observed in the cylindrical larvae of Lithocolletis is observed in the above-mentioned changes of the larvae of Gracilaria. Often as many as ten or fifteen larvae are found in a single blotch on the leaf. I succeeded in rearing the larvae easily by simply transferring leaves containing them to a box, in which I packed many leaves closely together. The leaves, thus packed, retained moisture and the larvae deserted the mines to wander about between the leaves, where they fed until ready for pupation. I am indebted to Professor Zeller, for the determ-

2 Journ. Cincinnati Soc. Nat. Hist., July 1879, also Separate, 22 p. [Psyche, Rec., no. 1805.] 
ination of the species of Gracilaria which I have had under observation.

In order to make the structure of the trophi and the arrangement of their chitinous supports more clear, I have prepared fig. 2-4, to accompany the following description.

The head of the early form (fig. 2) is much flattened. It has, upon its dorsal surface, two stout chitinous supports, which pass anteriorly to a point above the labrum, where they nearly meet, then turning lat-

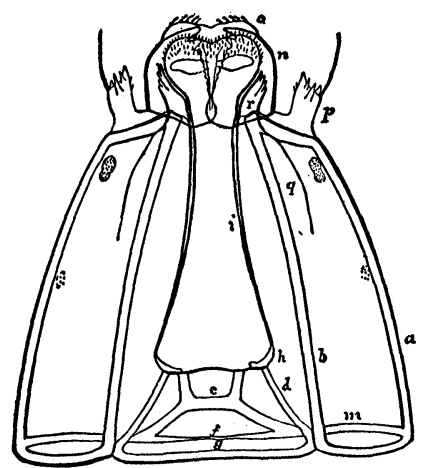

Fig. 2. - Ventral view of the head of Gracilaria syringella in its early larval stages: 0 , labrum ; $n$, mandible; $r$, maxilla ; $p$, antenna; $a$, $b, d, e, f, g, h, i, m$, chitinous supports explained in the text; $q$, depression between the basal support of the maxilla and the ventral surface of the head.

erally and ventrally, at nearly right angles to their previous direction, they join with other chitinous supports to form the sockets of the mandibular joints. Posteriorly these two dorsal supports (the anterior portions of which are not seen in fig. 2) approximate slightly and are connected by a transverse support (fig. $2, e$ ) ; rapidly diverging again they join the ring which passes around the posterior portion of the head (fig. $2, f, m, g$ ). From the lateral por- tions of this ring there passes forward, on each side, a support (fig. 2, $a$ ), which turns suddenly inward and ventrally behind the antenna (fig. 2, $p$ ), and helps to form the socket of the joint of the mandible. About half way between the lateral supports (fig. $2, a)$ and the middle of the ventral portion of the head, on each side, there passes forward from the ring which surrounds the posterior portion of the head another support (fig. 2, $b$ ), which also helps to form the socket of the mandibular joint. From the points where the last-mentioned supports join the posterior ring, supports (fig. $2, d$ ) pass anteriorly and obliquely toward the dorsal side of the head, joining the dorsal supports about midway between $e$ and the labrum.

The labrum of the early form (fig. 2,o) is supported beneath the diver rent anterior extremities of the dorsal chitinous supports of the head in such a manner as to be capable, not only of some protrusion and retraction, but also of a slight lateral motion. The labrum is bilobed, each lobe bearing five incurved spines, and has a very delicate grooving (fig. 3,o).

The mandibles of the early form (fig. 2 and $3, n)$ are strongly chitinized. They are of a generally triangular form, strongly rounded on the outer side and toothed on the inner side. Two prominent apical teeth are followed by a number of smaller ones. On the under-side of each mandible, near the middle of the proximal end, is a rounded protuberance, which fits into a socket formed by the union of the supports $a$ and $b$ with the laterally divergent anterior portions of the dorsal supports of the head, thus forming the mandibular joint. The pinniform extensor muscles of 
the mandibles have their insertion on the exterior proximal angle of each mandible and their origin on the chitin supports $a$ and $b$. The broadly pinniform flexor muscles of the mandibles have their insertion on the interior proximal angle of each mandible, and their origin on the chitinous supports $a$ and $m$ and on those which pass anteriorly and posteriorly from the support $e$; they thus lie dorsally and the extensors ventrally. The mandibles are directed exactly anteriorly, in the axis of the body ; and not ventrally.

The maxillae (fig. 2 and $3, r$ ) and the labium (fig. $3, v$ ) in the early form are attached to a common protrusile basis, the limits of which are partly indicated at $q$ (fig.2). The maxillae are very rudimentary, but that they are maxillae is shown by their being cleft, for if they were labial palpi they would not be cleft, but would probably be jointed. Further, as nearly as could be determined from a number of larvae found in the act of molting, at the time when they pass from the earlier to the later form, the maxillae of the later form were drawn from the skins of these cleft appendages. In still further support of the view that these mouth-parts are maxillae is their position, which is with their apical extremities slightly above the level of the labium, as can easily be seen by careful focusing with a high-power objective. The maxillae of the early form, then, are only lateral, outwardly-curved processes, each side of, and attached to the same support as the labium.

The labium of the early form (fig. $3, v$ ) is bilobed, with a few delicate grooves and thickenings, and is covered distally with a rasp of fine spines. It can be protruded,

together with the maxillae, beyond the extremities of the mandibles, and has a slight lateral motion. No traces of a spinneret are visible in the early form of larvae.

The support common to the maxillae and labium consists of two chitinous rods (fig. 2, i) passing posteriorly, diverging slightly, and then suddenly curving inward. The support is retracted by a muscle between the posterior ends of these chitinous rods (fig. $2, h$ ) and a part (fig. $2, g)$ of the ring at the posterior portion of the head. I was unable to discover
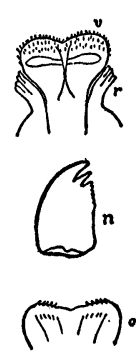

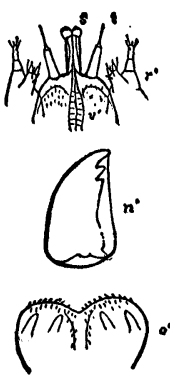

Fig. 3. - Comparison of the separated mouthparts of the early and later larval stages of Gracilaria syringella: $v, v^{\prime}$, labium of each form; $t$, labial palpus of later form.

any opposing muscle, and I think the labiomaxillary support is protruded by the action of the fluids of the head.

After the molting by which the larva enters upon its later or more cylindrical stages, the head becomes broader and thicker in proportion to its length, a few hairs appear on its anterior portions, the mouth-parts are directed a little ventrally from the axis of the body (fig. 4), and the condition of the trophi and their supports is as follows:-

The chitinous supports of the parts of the head are somewhat modified from what 
they were in the early form of larva, altho they are only a further elaboration of the same plan. The support $e$ (fig. 2) has become so reduced that the dorsal supports appear simply to cross one another (fig. 4, $e$ ). The supports which pass anteriorly from $e$ have united at their ends to form a clypeus (not shown in the figure). The support $f$ (fig. 2), which was slender in the early form, has entirely disappeared. The supports $\alpha$ and $m$ remain essentially the same as they were in the early form, but $b$, which at first united almost directly with $d$, has become separated from it, to allow of the interposition of a support $c$, which passes forward and unites, at $l$, with a branch $(k)$ from $b$, the whole portion at $l$ serving as attachment for a muscle to extend the labium and maxillae. The chitinous supports of the labium and maxillae have changed, as will be seen later.

The labrum (fig. 4, o ; fig. 3, o') has nearly the same outline as in the early form. The anterior portion, especially in the very last larval stage, is beset with hairs. It has two oblique thickenings in each lobe, and a $Y$-shaped thickening through the middle. The labrum is protrusile, retractile, and slightly movable laterally, as in the early form.

The mandibles (fig. $4, n$; fig. $3, n^{\prime}$ ) have characters similar to those which they had in the early form. The small teeth are, however, absent, and, in their place, a ridge extends along the under side of the mandible from the large apical teeth to the base. The origin and insertion of the extensor and flexor muscles are on places corresponding to their origin and insertion in the early form.
The maxillae in the later form (fig. 4, $r$; fig. $3, r^{\prime}$ ) have undergone considerable change in their appearance from that in the early form. They are now of the form common to lepidopterous larvae - an outward jointed portion, the maxillary palpus, and a double inner jointed portion, the maxilla proper.

The labium (fig. 3, $v^{\prime}$ ) has, in the later form, developed a pair of jointed labial palpi and a tubular spinneret. The proximal portion is hairy. Not only the spinneret, but also the labium itself, can be

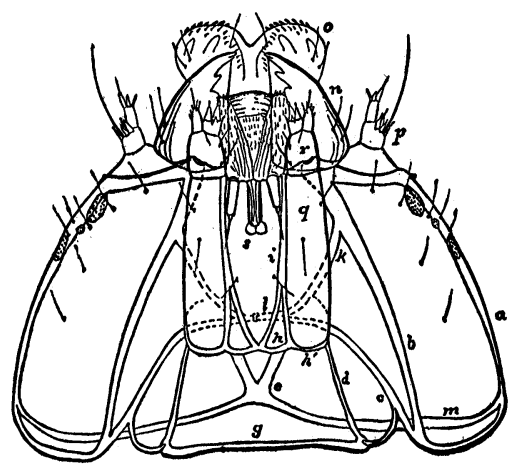

Frg. 4. - Ventral view of the head of Gracila ria syringella in its later larval stages: $s$, spinneret; other letters as in fig. 2 , or explained in text.

turned under, so that the labial palpi are directed posteriorly. The position shown in fig. 3 is with extended labium; in fig. 4 , with labium folded back.

The supports which bore the labium and maxillae in the early stages (fig. $2, i$ ) are greatly modified in the later stages. The support $i$ (fig. 4) divides posteriorly into two parts, between the ends of which extends a support, $h$ (fig. 4). The slightly developed line of demarcation between the 
maxilla and the under surface of the head (fig. 2, $q$ ) has become a clearly defined line, and the whole supporting framework of the labium and maxillae approaches a rectangular form, limited posteriorly by chitinous supports (fig. $4, h, h^{\prime}$ ). Muscles extend from these chitinous supports, $h, h^{\prime}$, anteriorly to the chitinous rod $l$ and posteriorly to the rod $g$. The action of these muscles protrudes or retracts the framework of the labium and maxillae, but, while the maxillae are simply pushed forward by this action, the labium is unfolded, or unrolled, so as to assume the position shown in fig. $3, v^{\prime}$.

If the form of the trophi in Gracilaria syringella, in its early larval stages, be compared with the form in the later larval stages, the modification of each part will be seen to increase in amount as the distance from the anterior part of the head increases, that is, the mandibles change more than the labrum, the maxillae more than the mandibles, and the labium most of all. By comparing, on fig. 3 , the mouthparts of the early and later forms, the changes of the labrum are seen to be mostly in markings, and in the number of hairs or spines; the changes of the mandible have been, to a slight extent, modifcations of form; the maxillae, while they existed before, are greatly modified in the later form; the labium most of all seems to have added to its structure and functions. This increase of complexity of the mouthparts toward the labium, which becomes more and more striking at each successive stage in many insects, is probably coordinate with the relations which these parts have to the surfaces on which the larvae walk, from which they feed, and, in many cases, on which they spin their silk.

This successive development of organs coordinate with their functions is well exemplified in the larvae of Gracilaria, of Lithocolletis, of Phyllocnistis ${ }^{8}$ and possibly of other Tineina, in which the early form of the larva is so different from its later form. In Gracilaria syringella, so long as the larvae feed only in a plane surface, and do not spin, no great difference is visible between the mouth-parts above the mandibles and those below them. Both labrum and labium exercise their simplest functions of pushing the food between, and keeping it subject to the action of the mandibles, and, perhaps, of sawing it out of the parenchyma by a lateral motion. But contemporaneous with the appearance of the later form of larval trophi, - the labium capable of turning under, and the better developed maxillae - the larva, now having its mandibles directed slightly ventrally, acquires the power of eating vertically to the surface of the leaf, and of spinning threads in all directions. At the same time its feet are developed, later it eats out from its mine, and becomes free. An externally well-differentiated dorsal and ventral surface seems to have been acquired from the time when the larva ceased to be pressed dorsally and ventrally between the upper and lower epidermis of its mine.

I have not had the opportunity to compare, by microscopic work, the larva of Gracilaria syringella with other larvae of Tineina; therefore the above observations may be regarded as quite incomplete.

Leipzig, 15 Aug. 1880.

${ }^{8}$ Psrche, May [July] 1880, v. 3, p. 67. 

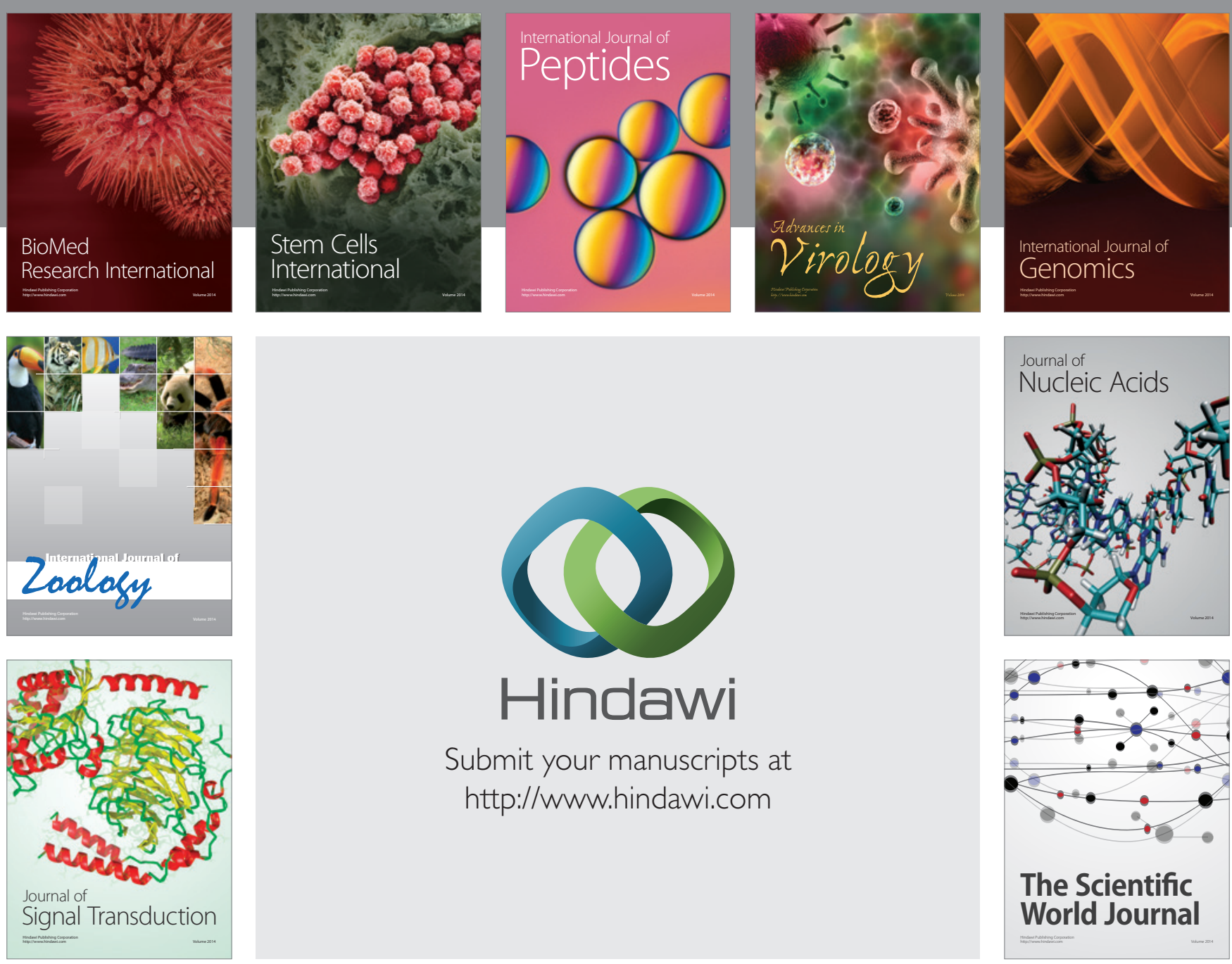

Submit your manuscripts at

http://www.hindawi.com
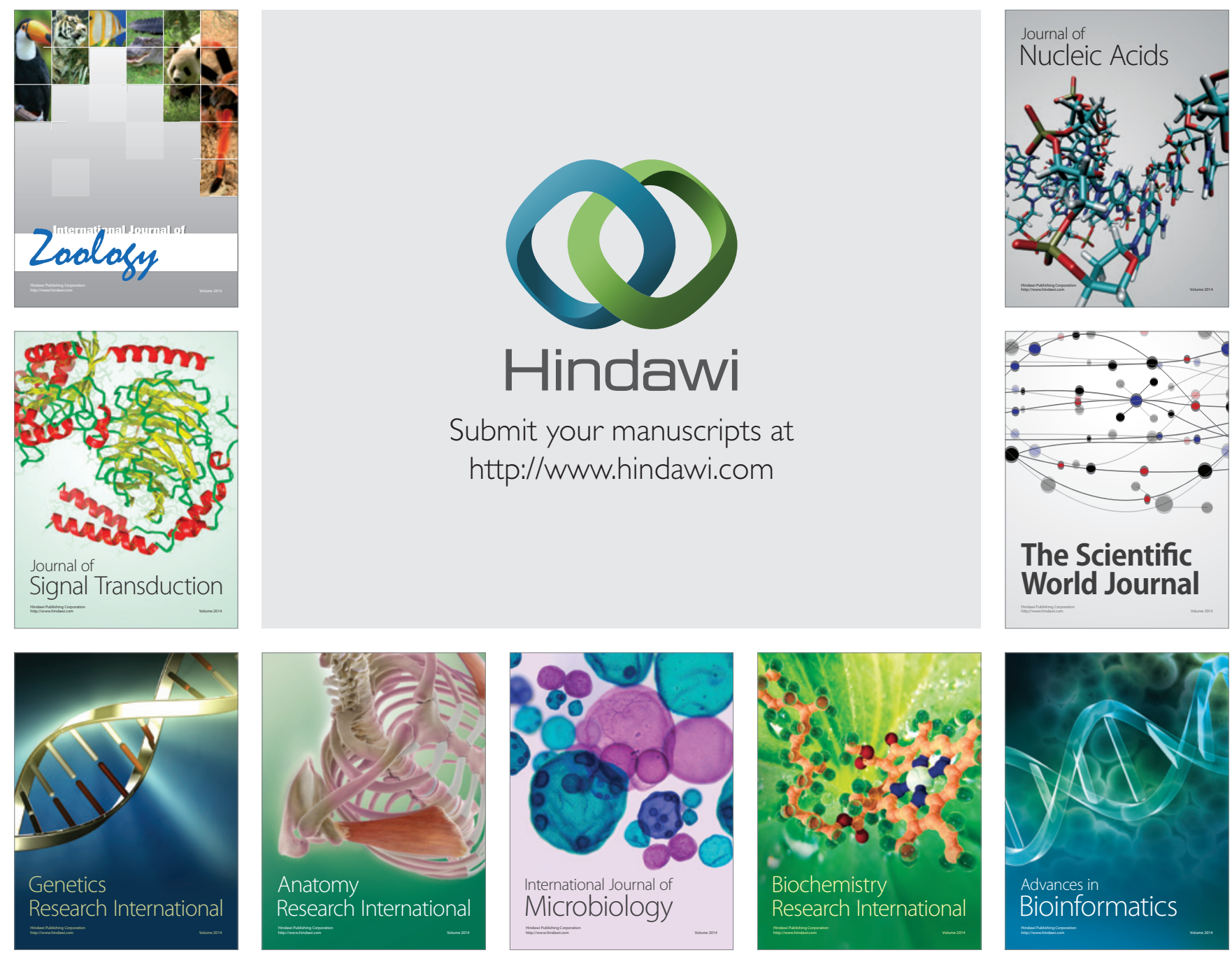

The Scientific World Journal
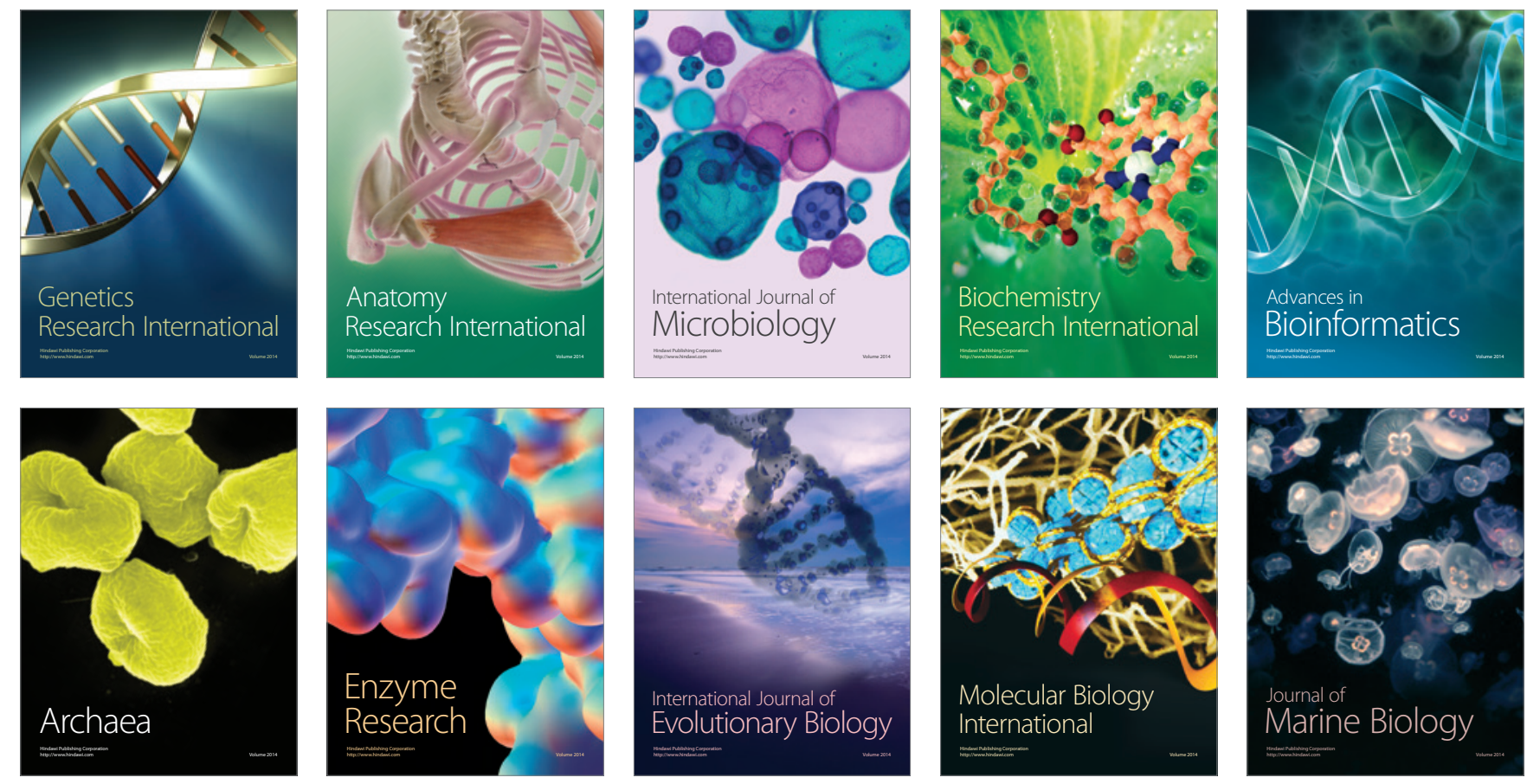